\title{
Geostatistical evaluation of satellite radar altimetry for high-resolution mapping of Lambert Glacier, Antarctica
}

\author{
Ute C. HeRzFeld, \\ Scripps Institution of Oceanography, University of California San Diego, La Jolla, CA 92093-0208, U.S.A. \\ Craig S. Lingle and Li-Her Lee \\ Geophysical Institute, University of Alaska Fairbanks, Fairbanks, AK 99775-0800, U.S.A.
}

\begin{abstract}
The potential of satellite radar altimetry for high-resolution mapping of Antarctic ice streams is evaluated, using retracked and slope-corrected data from the Lambert Glacier and Amery Ice Shelf area, East Antarctica, acquired by Geosat during the Exact Repeat Mission (ERM), 1986-89. The map area includes lower Lambert Glacier north of $72.18^{\circ} \mathrm{S}$, the southern Amery Ice Shelf, and the grounded inland ice sheet on both sides. The Geosat ERM altimetry is found to provide substantially more complete coverage than the 1978 Seasat altimetry, due to improved tracking. Variogram methods are used to estimate the noise levels in the data as a function of position throughout the map area. The spatial structure in the data is quantified by constructing experimental variograms using altimetry from the area of the grounding zone of Lambert Glacier, which is the area chiefly of interest in this topographically complex region. Kriging is employed to invert the along-track height measurements onto a fine-scale $3 \mathrm{~km}$ grid. The unsmoothed along-track Geosat ERM altimetry yields spatially continuous maps showing the main topographic features of lower Lambert Glacier, upper Amery Ice Shelf and the adjacent inland ice sheet. The probable position of the grounding line of Lambert Glacier is identified from a break in slope at the grounded ice/floating ice transition. The approximate standard error of the kriged map is inferred from the data noise levels.
\end{abstract}

\section{INTRODUCTION}

Fast-sliding ice streams and outlet glaciers have surface slopes related to the driving stress, and irregular topography with undulations reflecting the underlying bed topography. The undulations suggest the presence of localized "sticking points" on the bed, which may exert significant influence on the flow (Whillans and others, 1989). In a recent inversion of high-resolution satellitederived velocity measurements on a West Antarctic ice stream (Bindschadler and Scambos, 1991), MacAyeal (1992) found that the distribution of basal friction derived from control theory is sensitive to the surface slopes. We therefore investigate the extent to which satellite radar altimetry can be utilized for high-resolution mapping of the topography of large ice streams and outlet glaciers, using Geosat ERM data from Lambert Glacier and upper Amery Ice Shelf (Fig. 1), which discharges an inland catchment area estimated at $870000 \mathrm{~km}^{2}$ (Giovinetto and Bentley, 1985). This is about $9 \%$ of the area of the entire grounded East Antarctic ice sheet.

Lower Lambert Glacier, its grounding zone, and upper Amery Ice Shelf (Fig. 1) are within the Geosat coverage, and orbit convergence at $72.1^{\circ} \mathrm{S}$ resulted in a dense data set for this area, particularly for Lambert Glacier. The Geosat altimeter, although similar to the earlier Seasat (1978) version, incorporated design improvements that enabled it to maintain track more effectively over the Antarctic and Greenland ice sheets.

A contour map of ice elevations is constructed from Geosat ERM data by computing a digital terrain model (DTM), defined by a grid over the map area and an algorithm assigning a value to each grid node. The algorithm employed is kriging, an optimum estimation method based on the theory of regionalized variables (e.g. Journel and Huijbregts, 1978). (For an application to glaciology see Herzfeld and Homlund, 1990.) Kriging is suitable for use with large data sets consisting of measurements arbitrarily distributed in two spatial dimensions, or distributed in a regular pattern such as along the repeat satellite ground tracks shown in Figure 2 (Herzfeld, 1990). The noise levels in the data are estimated as a function of position throughout the map area using variogram methods (Lingle and others, 1990). The standard error of the kriged map is estimated from the inferred noise levels in the data. A $3 \mathrm{~km}$ grid interval is chosen because that is roughly three times the ice thickness in the vicinity of the grounding line of Lambert Glacer. The horizontal resolution of the DTM should thus be sufficient for numerical models that take into account longitudinal stress gradients, while being coarse enough to warrant neglecting the " $T$ term" (a double 


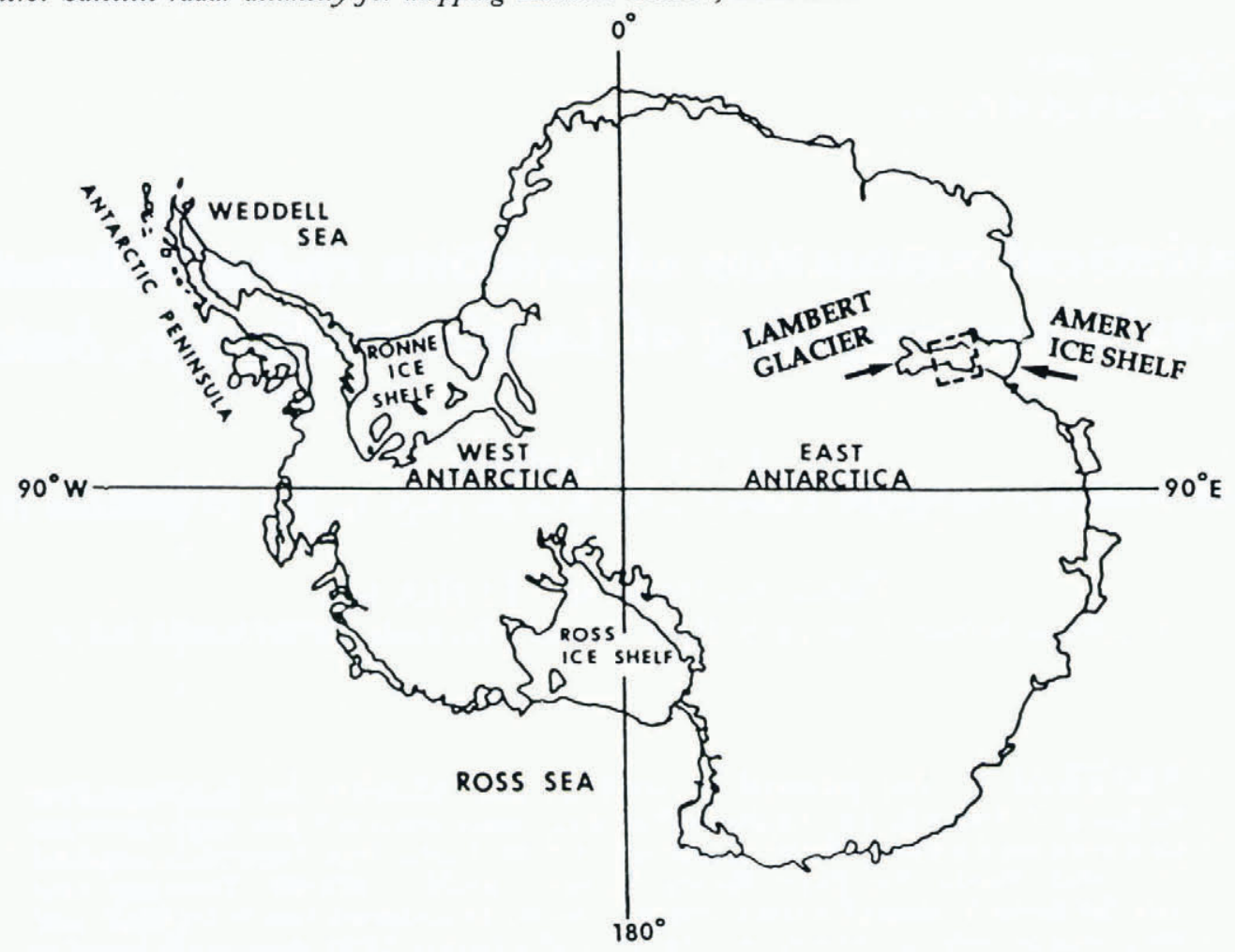

Fig. 1. Antarctica, with Lambert Glacier and Amery Ice Shelf indicated. The study area (box) is $70.5^{\circ}-72.1^{\circ} \mathrm{S}, 67^{\circ}-$ $73^{\circ} \mathrm{E}$, or in UTM coordinates, $171 \mathrm{~km}$ north-south by $204 \mathrm{~km}$ east-west.

integral over a coordinate perpendicular to the glacier surface of the second derivative of the shear stress, in the longitudinal direction) in the longitudinal stress equilibrium equation (Kamb and Echelmeyer, 1986). An interpretation of the results is given.

\section{DATA PROGESSING AND SPATIAL DISTRIBUTION}

Geosat ERM altimeter data from the Antarctic ice sheet have been reduced using Goddard Earth Model (GEM) T2 orbits (Marsh and others, 1989), and corrected for (i) tracking errors, using the method of Martin and others

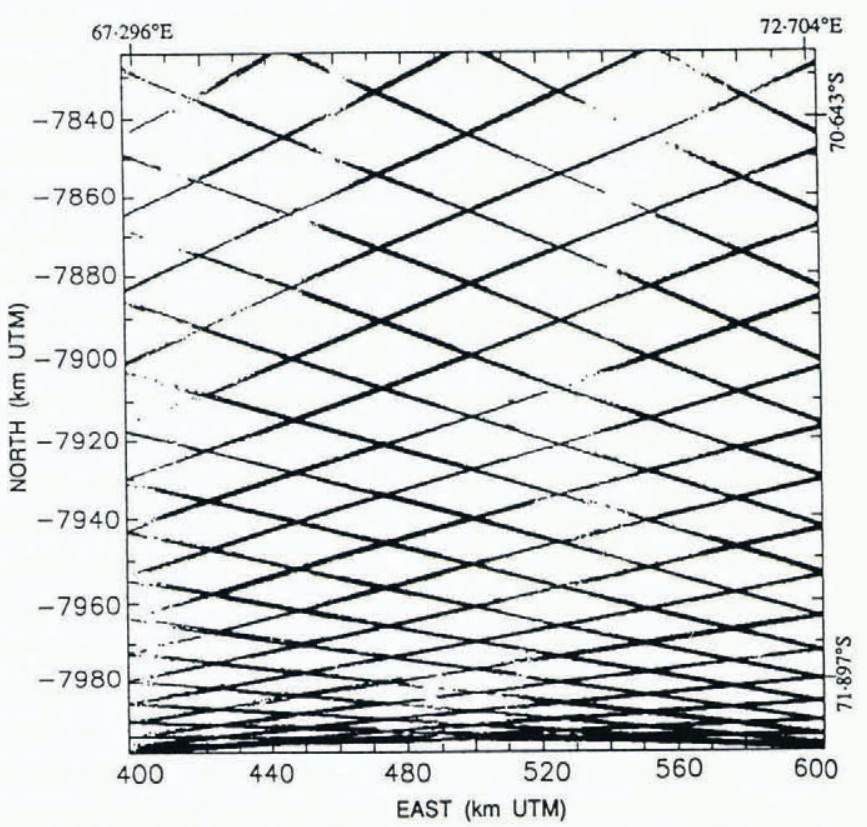

Fig. 2. Geosat ERM ground tracks in the Lambert Glacier study area.
(1983), (ii) atmospheric effects and solid Earth tides as described by Zwally and others (1983), and (iii) slopeinduced errors as described by Brenner and others (1983), by the ice-sheet altimetry group at NASA Goddard Space Flight Center. The retracked Geosat ERM altimetry employed in this study extend from 9 November 1986 through 9 January 1989. This $792 \mathrm{~d}$ ( 2.17 year) period included $4617 \mathrm{~d}$ orbit repeat cycles, and yielded 116204 measurements of surface height throughout the map area. The GEM T2 orbits used in this preliminary study, which have a radial precision of about $0.35 \mathrm{~m}$ r.m.s. (Haines and others, 1990), have not been adjusted into a common ocean surface. The altimeter-derived surface heights are with respect to the WGS 1984 ellipsoid.

The distribution of the along-track data is shown in Figure 2, which is a plot of all the individual measurement locations along the Geosat ERM ground tracks. The measurements are spaced at $662 \mathrm{~m}$ along the satellite tracks, for the $10 \mathrm{~s}^{-1}$ data used in ice-sheet altimetry. The ground tracks, which form a regular pattern because of the $17 \mathrm{~d}$ repeat cycle, are "fuzzy" because of the transverse orbit repeat variability of about $1 \mathrm{~km}$. The diamond-shaped gaps are approximately $40 \mathrm{~km}$ east-west by $20 \mathrm{~km}$ north-south in the northern map area. The gaps become smaller in the southern map area due to convergence of the orbits at $72.1^{\circ} \mathrm{S}$, at the southern map boundary. The continuity of coverage is very high relative to Seasat altimetry (compare to figure 2 of Brooks and others (1983), and to figure 4 of Zwally and others (1987)).

\section{MAP PROJECTION}

The map area, which extends from $70.5^{\circ}$ to $72.1^{\circ} \mathrm{S}, 67^{\circ}$ to $73^{\circ} \mathrm{E}$, is $171 \mathrm{~km}$ north-south by $204 \mathrm{~km}$ east-west, when 
transformed to a rectangular area on a Universal Transverse Mercator (UTM) projection (Snyder, 1987). Use of this projection results in (i) very low distortion, (ii) an orthogonal coordinate system, and (iii) distances that are defined in meters. Orthogonal coordinates are needed in kriging because the methodology includes a number of distance-dependent selection and interpolation algorithms. The datums are $0 \mathrm{~m}$ at the Equator for the north-south coordinate (northing with north positive), and $500000 \mathrm{~m}$ at the central medidian, $70^{\circ} \mathrm{E}$, for the east-west coordinate (easting with east positive).

\section{VARIOGRAPHY}

The variogram is the spatial structure function - or spatial continuity function - used in geostatistics. Here, we employ variography in the estimation of a map showing altimetry noise levels and as a step in kriging. The ice elevation is considered a regionalized variable $z(x)$, defined throughout a two-dimensional region $D$ and characterized by a structural aspect and a random variation (Journel and Huijbregts, 1978). The variogram is calculated in bins according to:

$$
\gamma(h)=\frac{1}{2 n} \sum_{i=1}^{n}\left[z\left(x_{i}\right)-z\left(x_{i}+h\right)\right]^{2}
$$

where $z\left(x_{i}\right), z\left(x_{i}+h\right)$ are samples taken at locations $x_{i}, x_{i}+h \in D$ respectively, and $n$ is the number of pairs separated by the vector $\mathbf{h}$. The spatial correlation among the elevations depends only on the vector $\mathbf{h}$ between the sample locations, a principle which the variogram shares with the structure function and the covariance function. The drift component $m$ corresponding to elevation pairs separated by $\mathbf{h}$ is

$$
m(\mathbf{h})=\frac{1}{n} \sum_{i=1}^{n}\left[z\left(x_{i}\right)-z\left(x_{i}+\mathbf{h}\right)\right]
$$

and the residual variogram is

$$
\operatorname{res}(\mathbf{h})=\gamma(\mathbf{h})-\frac{1}{2} m(\mathbf{h})^{2} .
$$

Note that, if the regionalized variable $z$ is stationary, then $m(\mathbf{h})=0$ and $\gamma(\mathbf{h})=\operatorname{res}(\mathbf{h})$ for all $\mathbf{h}$.

The experimental variograms calculated from the data are fitted by analytical variogram models to describe the transition from the strong covariation typical of closely neighboring samples to the weaker covariation typical of samples that are farther apart. The variogram model is characterized by its function type - which has to meet certain mathematical requirements so the inverse problem in the kriging step has a unique solution - and by parameters, which are the nugget effect $C_{0}$, the sill $C$ (where $C_{0}$ and $C$ are non-negative real numbers), and the range $a$ (where $a$ is a positive real number). The nugget effect or zero-lag intercept is the residual variance of resampling at the same location (see section on noise levels, below). The sill represents the a priori variance of the measurements. Elevation measurements separated by lags less than the range are spatially correlated. The range thus defines the maximum distance over which interpolation is meaningful. A linear variogram model with total sill $C_{0}+C$ and range $a$ is given by

$$
\gamma(\mathbf{h})= \begin{cases}C_{0}+\frac{C}{a}|\mathbf{h}| & \text { if }|\mathbf{h}| \leq a \\ C_{0}+\stackrel{C}{C} & \text { if }|\mathbf{h}|>a .\end{cases}
$$

A Gaussian variogram, which is defined by

$$
\gamma(\mathbf{h})=C_{0}+C\left(1-\exp \left(-\frac{\mathbf{h}^{2}}{a^{2}}\right)\right)
$$

has a practical or quasi range of $a^{\prime}=\sqrt{3} a$ with $\gamma\left(a^{\prime}\right) \approx C_{0}+0.95 C$ (for a Gaussian distribution). The differentiability of the variogram at $\mathbf{h}=0$ is related to the smoothness of the regionalized variable. A linear variogram is associated with a regionalized variable that is continuous in a mean-square sense. A regionalized variable with a Gaussian variogram is mean-square differentiable. Use of a smoother variogram in the kriging estimation results in a smoother map.

\section{ALTIMETRY NOISE LEVELS FROM VARIO. GRAMS}

The noise levels in the data are estimated as a function of position throughout the map area using a method analogous to that described by Lingle and others (1990). Briefly, the nearest 1000 height measurements (roughly the minimum needed to obtain "well-behaved" variograms) are identified within the circular neighborhood surrounding each node of a square grid with node spacing $10 \mathrm{~km}$. These data are then used to compute an experimental residual variogram for the local neighborhood of each grid point, using Equation (3) (this differs from the method used by Lingle and others (1990) for computation of residual variograms). The variogram for each grid point is extrapolated to zero lag $(h=0)$ using a polynomial least-squares fitting procedure, and the noise level is obtained as the square root of the zero-lag intercept, which is the standard error of the measurements in the local neighborhood of the grid point. Fourthdegree polynomials are employed, and are used only for extrapolating the variograms to zero lag. The polynomials thus need not (and do not) satisfy the mathematical constraints that analytical variogram models are subject to. The data noise estimates obtained in this way do not require a priori knowledge of instrument calibration, and represent the effects of all factors contributing to scatter in the data, including r.m.s. orbit error, systematic bias between ascending and descending orbits, noise caused by back-scatter from offnadir undulations, and seasonal variations in penetration depth. Small-scale geophysical variations in the data cannot be discriminated from noise, however, and are thus incorporated in the "noise levels". Crevasses are examples of such features.

The data noise levels throughout the map area, in meters, are shown in Figure 3, which indicates that the noise levels reflect the ice topography. The maximum noise levels (up to $150+\mathrm{m}$ ) occur along the northwest boundary, where the American Geographical Society Map of Antarctica shows that the terrain is mountainous. The relatively low noise levels $(3-10 \mathrm{~m})$ in the northcentral map area are characteristic of data back-scattered from the smooth surface of Amery Ice Shelf. The higher 


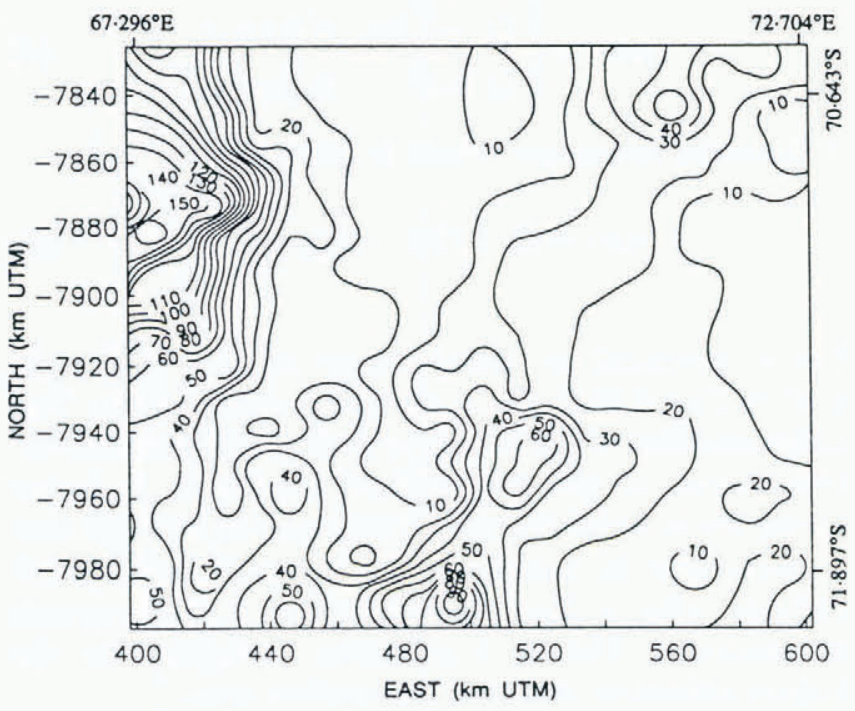

Fig. 3. Altimetry noise levels throughout the map area, computed using the variogram method (see text).

noise levels $(10 \mathrm{~m}$ to about $50 \mathrm{~m}$ ) in the south-central to southwest map area reflect the rougher and more undulating surface of grounded Lambert Glacier. The lower noise levels $(10-20 \mathrm{~m})$ along the eastern (right) map boundary reflect the relatively smooth surface of the high inland ice sheet. A "ridge" of higher noise levels coincides with the break-in-slope along the eastern margin of the glacier and ice shelf (see Figs 5 and 6).

\section{GEOSTATISTICAL COMPUTATION OF DIGITAL TERRAIN MODELS (DTM)}

Kriging methods comprise a family of least-squares based on spatial estimation methods (Journel and Huijbregts, 1978). In this study, ordinary kriging, i.e. universal kriging of order 0 , is employed for computation of the

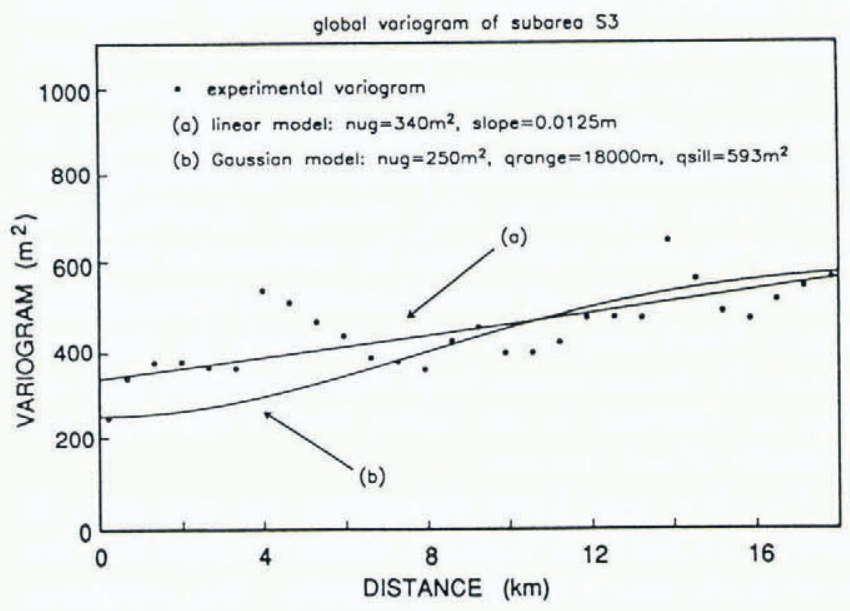

Fig. 4. Experimental variogram from sub-area S3 (marked on Figure 5) (discrete points), showing linear model (Equation (7)) used to krige DTM shown in Figure 5, and Gaussian model (Equation (5)) used to krige the DTM shown in Figures 6 and 7.
DTMs. The value $z_{0}=z\left(x_{0}\right)$ at a node $x_{0}$ is estimated using

$$
z_{0}^{*}=\sum_{i=1}^{n} \alpha_{i} z_{i}
$$

where the $z_{i}$ are altimeter-derived elevations $z_{i}(x)$ at locations $x_{i}, i=1, \ldots, n$, in the neighborhood of $x_{0}$. The coefficients $\alpha_{i}$ are determined such that the estimation error has minimum variance and the estimation is unbiased. The unbiasedness condition for ordinary kriging is $\alpha_{1}+\alpha_{2}+\ldots+\alpha_{n}=1$.

A solution is obtained using the variogram model derived from the experimental variograms. (For a derivation of the ordinary kriging system see Herzfeld, 1992). The software used is specifically designed to evaluate data from geophysical line surveys (Herzfeld, 1990).

Elevation data from a sub-area S3 on the surface of Lambert Glacier are selected for computation of directional variograms and residual variograms (Fig. 4), in order to use a spatial structure in the estimation that is appropriate for the area of main interest. To locate the grounding line it is necessary to detect a small change-inslope on lower Lambert Glacier, so the spatial characteristics of the data from this sub-area are deemed most important. A consequence of using a single variogram for the entire DTM is that the rough areas along both sides of Lambert Glacier are somewhat smoothed. These areas, however, are not of primary interest in this study.

Variograms and residual variograms are similar for most lags, and can be fitted with the same model. The experimental directional variograms show effects that can be ascribed to the ground track pattern (i.e. jumps or wave-like patterns with approximately constant wavelength, superimposed on increasing variogram values). These patterns are disregarded in the model fitting. The linear model best describing the spatial structure in subarea $\mathrm{s} 3$ is

$$
\gamma(\mathbf{h})=340+0.0125 h\left(\mathrm{~m}^{2}\right)
$$

(Fig. 4). The zero-lag intercept of $340 \mathrm{~m}^{2}$ (Equation (7)) implies a mean noise level of $18 \mathrm{~m}$ in the vicinity of the Lambert Glacier grounding line, which is roughly consistent with the independently computed data noise map shown in Figure 3.

The DTM is computed from the along-track data using variogram values from Equation (7). Each node of the $3 \mathrm{~km}$ grid is kriged using the nearest 16 altimeterderived elevation measurements, selected with a quadrant seach algorithm (to avoid selecting only data distributed along a single ground track) controlled by a suite of parameters. The DTM has 68 grid nodes east-west by 57 grid nodes north-south. The corresponding map, with elevations in meters above the WGS 1984 ellipsoid, is shown in Figure 5.

To suppress somewhat further the effects of high noise levels in the data, a Gaussian variogram (see Figure 4 and Equation (5)) is used in a second run of the kriging procedure. The effect of a Gaussian variogram is that similar weights are assigned to the data closest to the grid nodes. The topographic effect is that the fine-scale roughness is smoothed. (Roughness on the scale of 


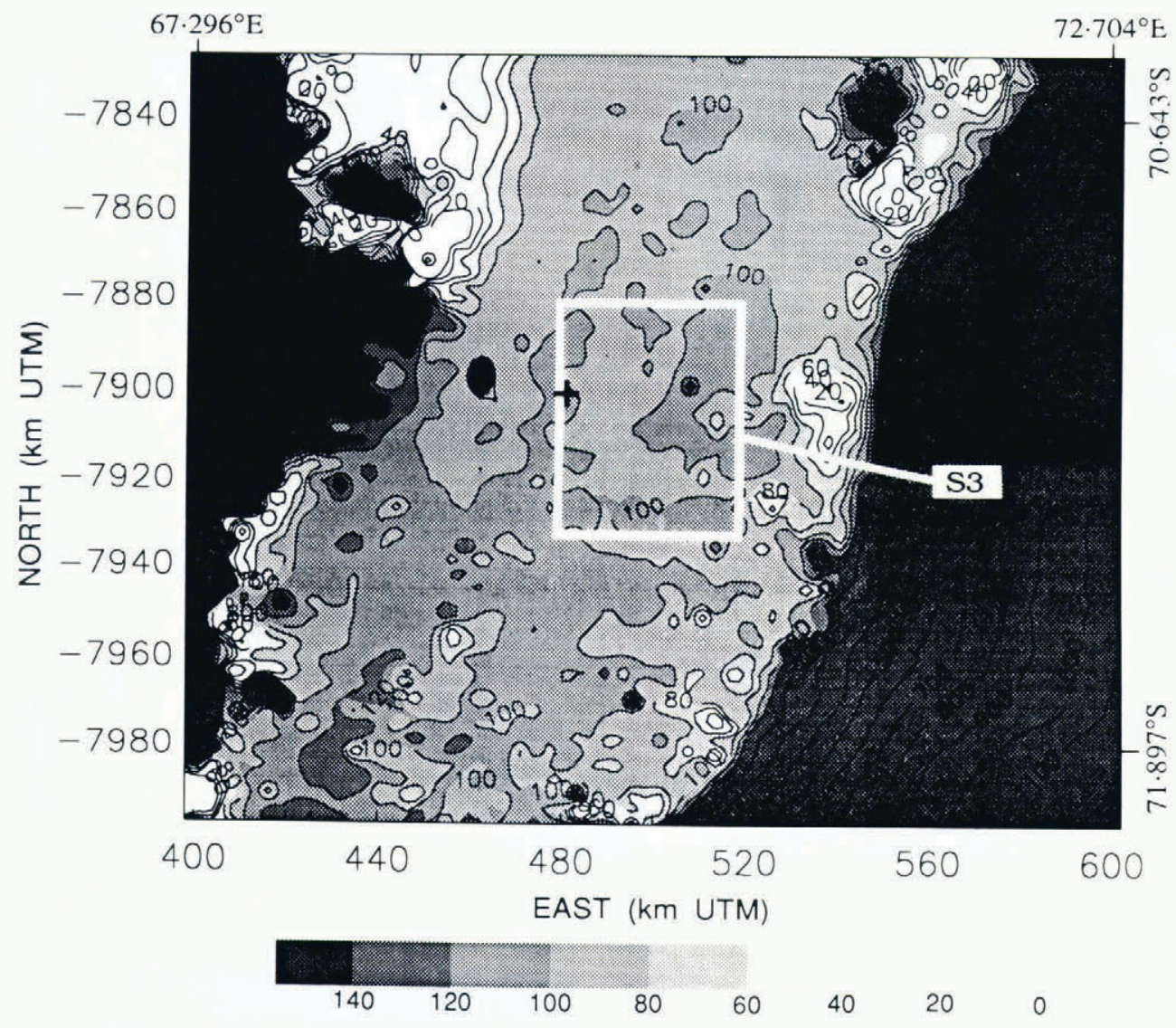

Fig. 5. Topography of lower Lambert Glacier and upper Amery Ice Shelf, with DTM kriged using the linear variogram model (Fig. 4). The apparent grounding line of Lambert Glacier (100 m contour) is accentuated in this gray-scale map. Elevations are in meters above the WGS 1984 ellipsoid. Location of sub-area S3 used for variogram calculation is indicated by the white box. The cross shows the location of the grounding line identified by Budd and others (1982) from optical leveling data.

individual crevasses or "small" crevasse fields should not be resolvable in a DTM with $3 \mathrm{~km}$ grid interval, although Partington and others (1987) showed that crevasse fields are detectable in the along-track, i.e. ungridded Seasat altimetry from Amery Ice Shelf). The Gaussian variogram model has a nugget effect of $250 \mathrm{~m}^{2}-$ corresponding to a mean noise level in the vicinity of the grounding line of $16 \mathrm{~m}$, which is also roughly consistent with the data noise map in Figure 3 - a quasi sill of $593 \mathrm{~m}^{2}$ and a quasi range of $18 \mathrm{~km}$. The variogram parameters are set such that at the quasi range, the quasi sill of the Gaussian model is equal to the $593 \mathrm{~m}^{2}$ sill of the linear model. The result is shown in Figure 6 as a map and in Figure 7 as a block diagram. The maps in Figures 5 and 6 are very similar. Areas of the same elevation on the glacier are somewhat more connected on the map based on the Gaussian variogram model (Fig. 6), however, than on the map based on the linear variogram model (Fig. 5). The major topographic features are the same, and in the same locations.

\section{ERROR ANALYSIS}

The kriging estimation standard deviation (Journel and
Huijbregts, 1989, p. 318) reflects simply the survey pattern. We therefore attempt to estimate the standard error of the kriged maps from the location-dependent data noise levels, using standard methods applicable to random error propagation through the kriging calculations. Taking this approach, it can be shown that

$$
s_{0}^{2}=\sigma_{0}^{2} \sum_{i=1}^{n} \alpha_{i}^{2}
$$

for the kriged elevation at node $x_{0}$, where $\sigma_{0}$ is the mean noise level for the data in the local neighborhood, and the $\alpha_{i}$ are the optimum weights for the node (see Equation (6)). In this study, the $\alpha_{i}$ were not saved along with the kriging output, but an approximate estimate of $s_{0}$ can be made by assuming the weights are all identical, which is equivalent to supposing that each node is calculated as an unweighted average of the surrounding $n$ height measurements. Using this approximation, $s_{0}$ is simply $\sigma_{0} / \sqrt{n}$, where $n=16$ as noted above. (This simplification may yield a somewhat optimistic estimate of the map error, because the implication is that the error can be decreased substantially by increasing the number of points used to krige each grid node. In kriging, however, one reaches a point of diminishing returns, 

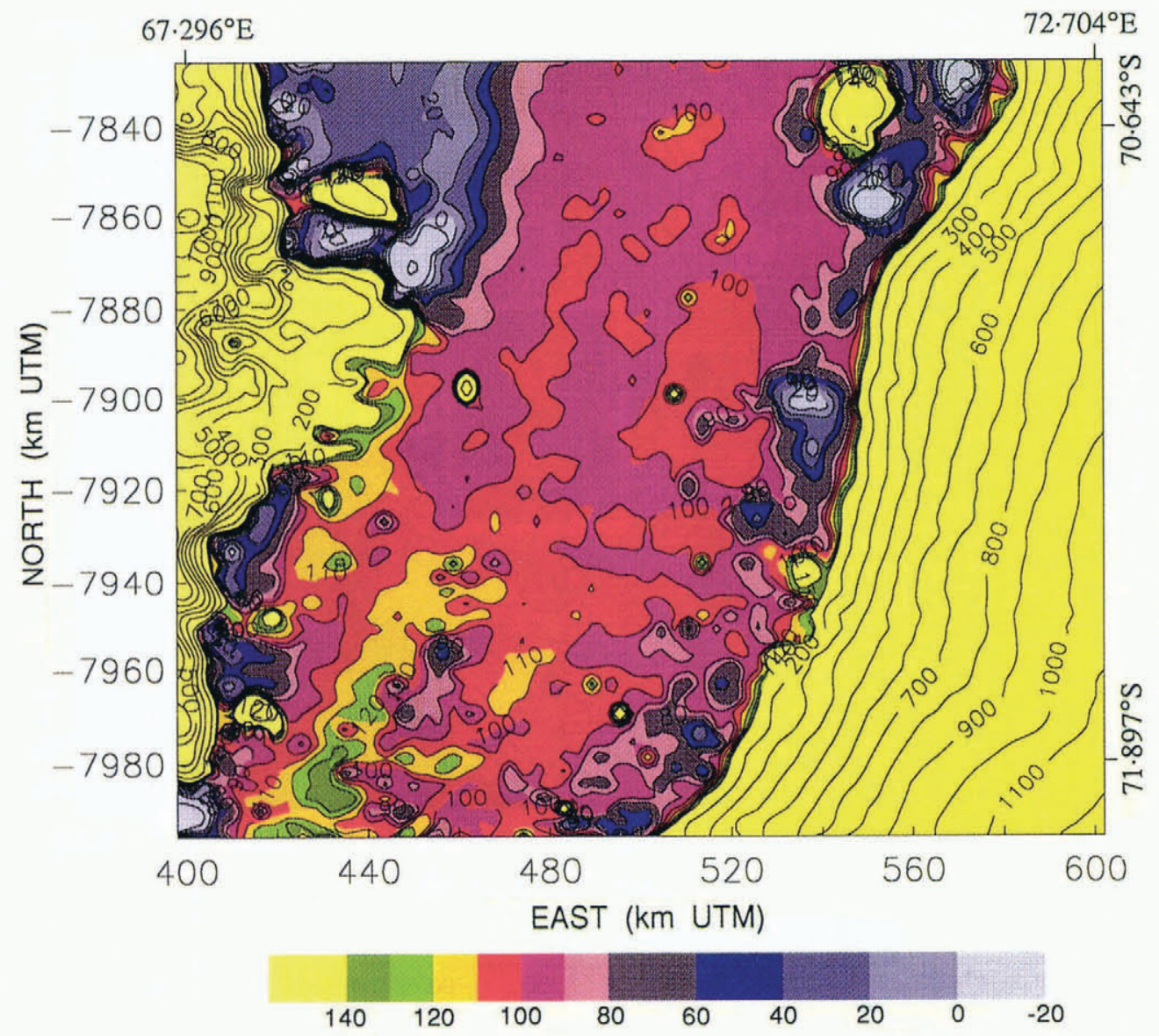

Fig. 6. Topography of lower Lambert Glacier and upper Amery Ice Shelf, with DTM kriged using the Gaussian variogram model (Fig. 4). The apparent location of the grounding line of Lambert Glacier is the boundary between red (higher) and purple (lower)meandering across the glacier approximately transverse to the flow direction. Elevations are in meters above the WGS 1984 ellipsoid.

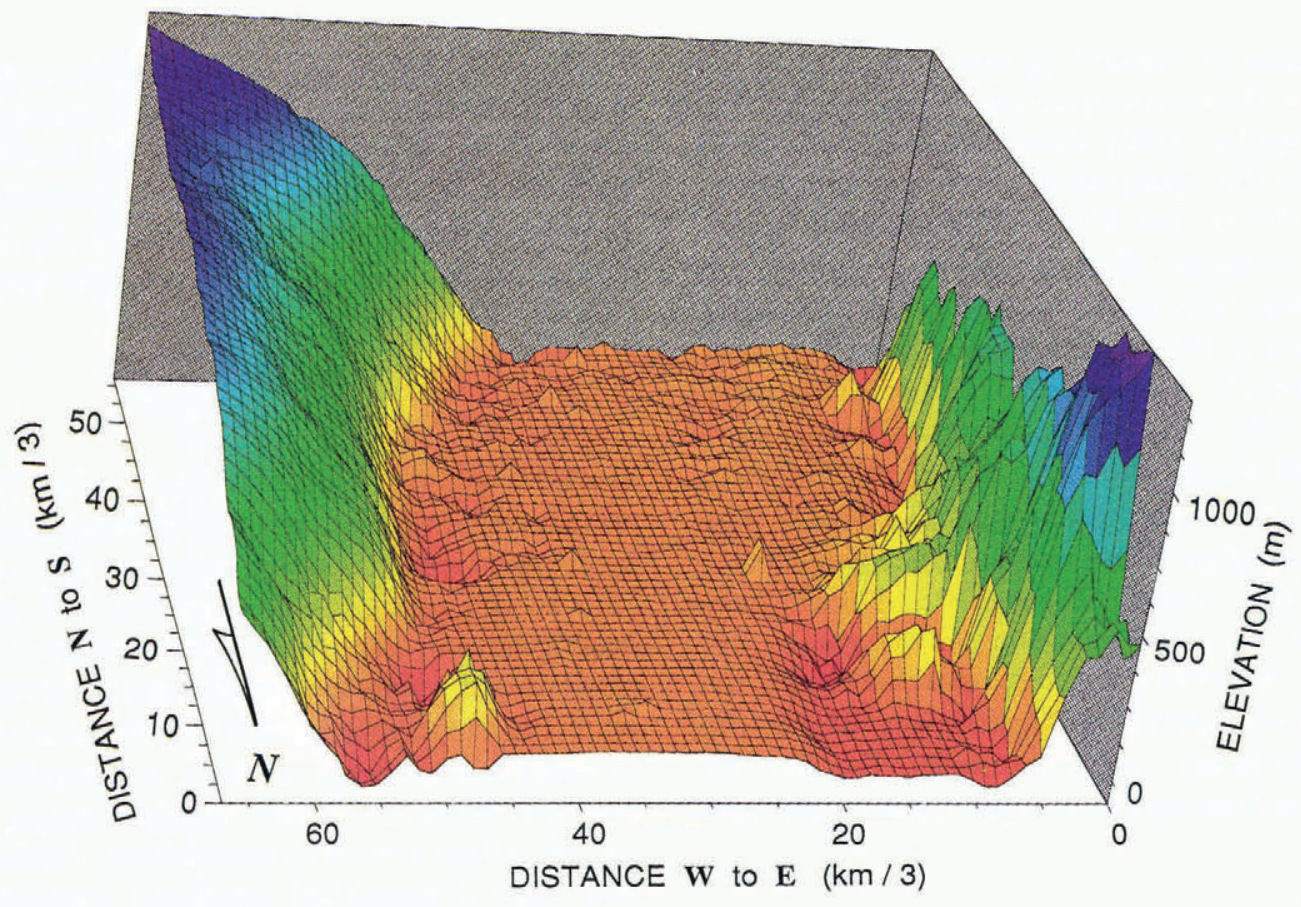

Fig. 7. Block diagram of upper Amery Ice Shelf (foreground) and lower Lambert Glacier (background), kriged with the Gaussian variogram model. The vertical axis is meters above the WGS 1984 ellipsoid. The horizontal axes give numbers of grid nodes (grid shown on block diagram), $3 \mathrm{~km}$ per grid interval. 


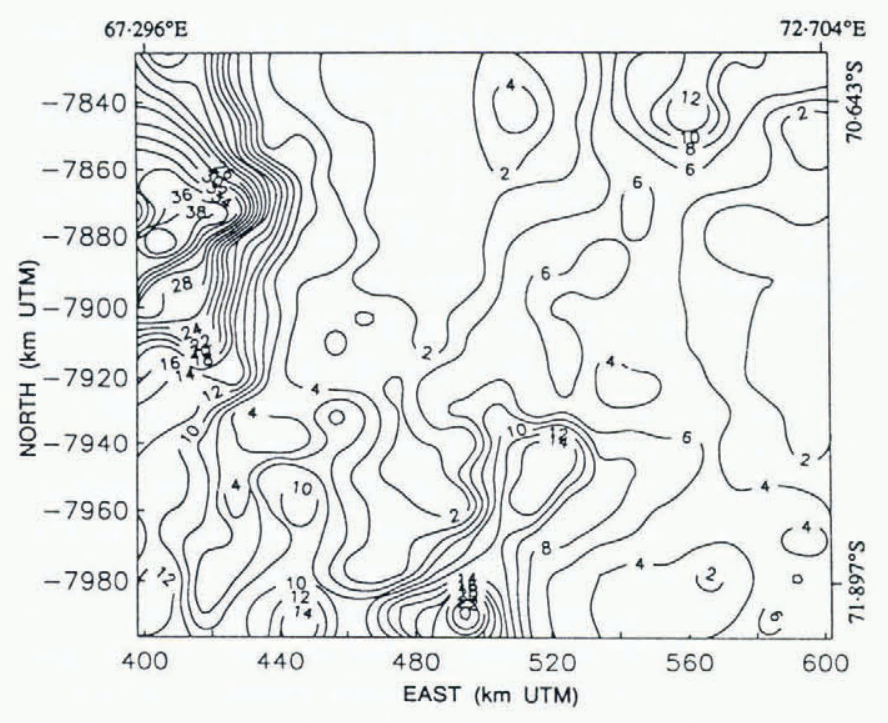

Fig. 8. Approximate standard error of kriged elevation maps, in meters (see text section on error analysis).

because points that are at greater distance have lesser weights.)

Figure 8 shows the approximate standard error of the DTMs shown in Figures 5, 6 and 7; it is roughly onefourth the data noise map shown in Figure 3, or 1-4 m on the flat Amery Ice Shelf, $4 \mathrm{~m}$ to about $14 \mathrm{~m}$ on the rougher Lambert Glacier, 2-4 $\mathrm{m}$ on the high East Antarctic ice sheet along the eastern map boundary, and up to $40 \mathrm{~m}$ in the region of mountainous nunataks along the northwest map boundary. There is also a "ridge" of higher map error - about 6-20 m corresponding to the break-in-slope along the eastern margin of Lambert Glacier and Amery Ice Shelf.

It should be noted that Equation (8) does not include systematic errors caused by the inability of the altimeter to "see into" the dips between undulations. The backscattered signals tend to be returned from the crests of undulations that are closest to the satellite, not from the nadir points, and the altimeter tends to "skip" from one high point to the next (Gundestrup and others, 1986). The slope corrections partially account for this.

\section{INTERPRETATION}

\section{Glacier topography and location of grounding line}

Most of the Amery Ice Shelf area mapped in this study is within the range 80-130 $\mathrm{m}$ above the WGS 1984 ellipsoid. It can be seen that the contours are more closely spaced and complex south of northing coordinates -7920 to $-7930 \mathrm{~km}$, suggesting grounded ice where basal undulations are transmitted to the surface through the fastsliding ice stream. There are a number of spikes (perhaps 6 ) on the surface of the ice shelf and glacier in Figures 57 , and these are caused by noise in the data. Beyond that, the irregular nature of the Lambert Glacier surface can be taken as a reflection of the more undulating and rougher surface characteristic of grounded ice.

The $100 \mathrm{~m}$ contour defines a break-in-slope suggestive of the grounding line. This break-in-slope can be seen in
Figure 6, where it appears as the boundary between purple and red. This apparent grounding line meanders across Lambert Glacier in an irregular fashion. The patchy areas of red above the $100 \mathrm{~m}$ contour farther north suggest the presence of a number of sea-floor shoals intersecting the bottom surface of the ice shelf immediately downstream. The entire area, from northing coordinates -7870 to -7920 (on the western side of the glacier), or to -7950 (on the eastern side of the glacier), can probably be considered the grounding zone. The gray-scale map of Figure 5 shows the apparent grounding line ( $100 \mathrm{~m}$ contour) and sea-floor shoals more clearly. The grounding line identified by Budd and others (1982) from optical leveling data, shown by the cross in Figure 5, is within this grounding zone.

Partington and others (1987) point out that the altimeter "sees" the grounding line before crossing it, when the direction of motion is up-glacier - or, conversely, after crossing it, when the direction of motion is down-glacier. An error of about $2-4 \mathrm{~km}$ is introduced, depending on the angle at which the ground track crosses the grounding line, if that effect is neglected. The data slope-correction procedure should counteract this effect, at least in part, but the "actual" grounding line may be displaced up-glacier on the order of $1 \mathrm{~km}$ to several kilometers from the apparent grounding line identified in Figures 5 and 6.

\section{Ice-shelf and glacier margins}

The block diagram in Figure 7 shows that Lambert Glacier and Amery Ice Shelf have lowered surface elevations corresponding to reduced ice thickness along the margins. These lowered surface elevations may be a consequence, at least in part, of enhanced vertical strain rates within the marginal shear zones. To show this, we adopt the conventional notation of ice mechanics. The stress tensor is $\sigma_{i j}$, subscripts $i, j$ represent directions $x, y, z$, where $x$ is positive down-glacier, $y$ is transverse, $z$ is vertical (positive up), and $x, y, z$ form a righthanded system, $\tau_{i j}$ are shear stress components, $\tau$ is the effective stress, $\dot{\epsilon}_{i j}$ is the strain-rate tensor, $B$ is the ice-hardness parameter, and $n \approx 3$. The generalized flow law of ice is (Nye, 1957):

$$
\dot{\epsilon}_{i j}=B^{-n} \tau^{n-1} \sigma_{i j}^{\prime} \quad\{i, j\} \subseteq\{x, y, z\}
$$

where

$$
2 \tau^{2}=\sigma_{x x}^{2}+\sigma_{y y}^{\prime 2}+\sigma_{z z}^{2}+2\left(\tau_{x y}^{2}+\tau_{y z}^{2}+\tau_{z x}^{2}\right)
$$

is the second invarient of the stress-deviator tensor,

$$
\sigma_{i j}^{\prime}=\sigma_{i j}-\frac{1}{3} \delta_{i j}\left(\sigma_{x x}+\sigma_{y y}+\sigma_{z z}\right)
$$

is the stress deviator tensor, and $\delta_{i j}=1$ if $i=j, \delta_{i j}=0$ if $i \neq j$.

Consider a point "far" from the sides of Amery Ice Shelf. Vertical shear is negligible (Sanderson and Doake, 1979), and $\tau_{x y}$ is small because the transverse velocity gradient is small (Allison, 1979; Budd and others, 1982), so

$$
\begin{aligned}
& \tau_{y z}=\tau_{z x}=0, \quad \tau_{x y} \approx 0, \quad \text { and } \\
& \dot{\epsilon}_{z z} \approx B^{-n}\left[\frac{1}{2}\left(\sigma_{x x}^{\prime 2}+\sigma_{y y}^{\prime 2}+\sigma_{z z}^{\prime 2}\right)\right]^{\frac{n-1}{2}} \sigma_{z z}^{\prime} .
\end{aligned}
$$


Within the zone of intense shear near the margins $\tau_{x y} \neq 0$, and is likely to be substantially larger than $\sigma_{x x}^{\prime}, \sigma_{y y}^{y}$ and $\sigma_{z z}^{\prime}$, so

$$
\dot{\epsilon}_{z z} \approx B^{-n}\left[\frac{1}{2}\left(\sigma_{x x}^{2}+\sigma_{y y}^{\prime 2}+\sigma_{z z}^{\prime 2}+2 \tau_{x y}^{2}\right)\right]^{\frac{n-1}{2}} \sigma_{z z}^{\prime} .
$$

Thus, if the longitudinal stress deviator components are comparable in both places, the vertical strain rate $\dot{\epsilon}_{z z}$ (within the ice-shelf marginal shear zones) $>\dot{\epsilon}_{z z}$ (far from the marginal shear zones). If the grounded Lambert Glacier is moving mostly by basal sliding, the same argument would also apply, approximately, within its marginal shear zones. To account for anisotropy, Jacka and Budd (1989) found that the r.h.s. of Equation (9) should be multiplied by an "enhancement factor" $E$, where for ice deforming in steady-state creep in compression with a preferred fabric, $E_{\sigma}$ can be as large as $\sim 3$ (i.e. $E_{\sigma}$ would multiply the r.h.s. of Equation (12)), while for ice undergoing steady-state shear deformation with a preferred fabric, $E_{\tau}$ can be as large as $\sim 8$ (i.e. $E_{\tau}$ would multiply the r.h.s. of Equation (13)). This suggests that the additional large shear-stress component $\tau_{x y}$ within the effective stress, combined with the effects of anisotropy, may be sufficient to account, at least in part, for the surface lowering along the sides of Lambert Glacier and Amery Ice Shelf. However, the optically levelled transverse elevation profile from upper Amery Ice Shelf in Budd and others (1982) shows that the elevations within the shear margins at the sides of the shelf are lower than the general surface by about $10-30 \mathrm{~m}$. On the altimetry-derived maps in Figures 5-7, the elevations within the side shear margins are (apparently) lower than the general surface by about $50 \mathrm{~m}$. Thus, "snagging", an effect caused by the tendency of the altimeter to "lock on" to a reflector while crossing a break-in-slope before regaining track, may also account for a significant fraction of the surface lowering within the shear margins shown by the altimetry maps.

\section{SUMMARY}

A geostatistical evaluation of the potential of satellite radar altimetry for high resolution mapping of Antarctic ice streams, carried out using Geosat ERM altimetry from lower Lambert Glacier and upper Amery Ice Shelf, East Antarctica, has shown that kriging can be used to obtain digital terrain models on a $3 \mathrm{~km}$ grid with an approximate standard error of about 4-14 m over the somewhat rugged surface of the grounded glacier and about $1-4 \mathrm{~m}$ over the flatter surface of the floating ice shelf (Fig. 8). The approximate standard errors of the DTMs are higher over the relatively steep slopes of the inland ice sheet immediately east of Amery Ice Shelf, and considerably higher (up to about $40+\mathrm{m}$ ) over a mountainous region characterized by nunataks projecting through the ice sheet immediately west of Lambert Glacier and Amery Ice Shelf. These estimates of map error are based on the spatially varying noise levels in the data determined using variogram methods, and do not take into account systematic errors caused by not adjusting the orbits into a common ocean surface, or by the inability of the altimeter to "see into" dips between undulations occurring over short spatial scales.
The DTMs reveal undulations on the surface of the grounded Lambert Glacier that appear to be expressions of bed topography transmitted through the fast-sliding ice stream to the surface. The surface elevations are apparently lower within the shear margins along the sides of the glacier and ice shelf. This may, in part, be a consequence of enhanced vertical strain rates caused by the additional large shear stress component within the effective stress in the flow law of ice within the shear margins. This effect may also be, in part, an artifact of altimeter "snagging" (see "Interpretation" above).

A break-in-slope at about the $100 \mathrm{~m}$ elevation contour (above the WGS 1984 ellipsoid) is interpreted as the probable location of the grounding line. This break in slope, which meanders across Lambert Glacier in an irregular fashion, separates the higher and more rugged surface of the glacier from the lower, smoother surface of the ice shelf. Local areas of higher elevation on the ice shelf downstream from the apparent grounding line suggest the presence of sea-floor shoals projecting into the bottom surface of the ice shelf. The grounding line identified by Budd and others (1982) from optical leveling data along the central flow line is within the area generally identified as the grounding zone in this study. The "actual" grounding line may be displaced on the order of $1 \mathrm{~km}$ to several kilometers up-glacier (south) from the apparent grounding line in Figures 5 and 6, because of the effect of the slope change.

\section{ACKNOWLEDGEMENTS}

This work was supported by NASA grant NAGW-2614 and NASA/GSFC grant NAG 5-1748 to C. S. Lingle, and NASA grant NAGW-2746 to U.C. Herzfeld. U.C. Herzfeld wishes to thank the Alexander von Humboldt-Foundation, Bonn, Germany, for a FeodorLynen-Fellowship. We thank H. J. Zwally, A. C. Brenner, J.P. Dimarzio and S. Fletcher for furnishing the retracked and slope-corrected altimetry used in this study and for assistance with reading the tapes, R. Guritz for technical assistance with the Alaska SAR Facility IIAS computing system, O. Skulason and D. Covey for programming assistance, D. Sandwell for use of a color plotter, C. Rata for help with plotting and J. Griffith for production of the final figures. We also thank two anonymous reviewers and N.W. Young for comments that improved the manuscript.

\section{REFERENCES}

Allison, I. 1979. The mass budget of the Lambert Glacier drainage basin, Antarctica. F. Glaciol., 22(87), 223235.

Bindschadler, R. A. and T. A. Scambos. 1991. Satelliteimage-derived velocity field of an Antarctic ice stream. Science, 252(5003), 242-246.

Brenner, A. C., R.A. Bindschadler, R.H. Thomas and H.J. Zwally. 1983. Slope-induced errors in radar altimetry over continental ice sheets. F. Geophys. Res., 88(C3), 1617-1623.

Brooks, R. L., R. S. Williams, Jr, J. G. Ferrigno and W. B. 
Krabill. 1983. Amery Ice Shelf topography from satellite radar altimetry. In Oliver, R. L., P. R. James and J. B. Jago, eds. Antarctic earth science. Cambridge, etc., Cambridge University Press, 441-445.

Budd, W. F., M.J. Corry and T. H. Jacka. 1982. Results from the Amery Ice Shelf Project. Ann. Glaciol., 3, 3641.

Giovinetto, M. B. and C. R. Bentley. 1985. Surface balance in ice drainage systems of Antarctica. Antarct. J. U.S., 20(4), 6-13.

Gundestrup, N. S., R. A. Bindschadler and H.J. Zwally. 1986. Seasat range measurements verified on a 3-D ice sheet. Ann. Glaciol., 8, 69-72.

Haines, B. J., G. H. Born, G. W. Rosborough, J. G. Marsh and R. G. Williamson. 1990. Precise orbit computation for the Geosat Exact Repeat Mission. 7. Geophys. Res., 95(C3), 2871-2885.

Herzfeld, U.C. 1990. Geostatistical software for evaluation of line survey data, applied to radio-echo soundings in glaciology. In Hanley, J. T. and D. F. Merriam, eds. Microcomputer application in geology II. New York, Pergamon Press, 119-136. (Computers and Geology 6.)

Herzfeld, U.C. 1992. Quantitative spatial models of Atlantic primary productivity: an application of geomathematics. 7. Geophys. Res., 97(C1), 717-732.

Herzfeld, U. C. and P. Holmlund. 1990. Geostatistics in glaciology: implications of a study of Scharffenbergbotnen, Dronning Maud Land, East Antarctica. Ann. Glaciol., 14, 107-110.

Jacka, T.H. and W. F. Budd. 1989. Isotropic and anisotropic flow relations for ice dynamics. Ann. Glaciol., 12, 81-84.

Journel, A. G. and C.J. Huijbregts. 1989. Mining geostatistics. Fourth printing with corrections. New York, Academic Press.

Kamb, B. and K. A. Echelmeyer. 1986. Stress-gradient coupling in glacier flow: IV. Effects of the " $T$ " term. J. Glaciol., 32(112), 342-349.

Lingle, C.S., A. C. Brenner and H.J. Zwally. 1990.
Satellite altimetry, semivariograms, and seasonal elevation changes in the ablation zone of West Greenland. Ann. Glaciol., 14, 158-163.

MacAyeal, D. R. 1992. The basal stress distribution of Ice Stream E, Antarctica, inferred by control methods. $\mathcal{J}$. Geophys. Res., 97(B1), 595-603.

Marsh, J.G. and 19 others. 1989. The GEM T2 gravitational model. NASA Tech. Memo. 100746.

Martin, T. V., H.J. Zwally, A. C. Brenner and R. A. Bindschadler. 1983. Analysis and retracking of continental ice sheet radar altimeter waveforms. $\mathcal{J}$. Geophys. Res., 88(C3), 1608-1616.

Nye, J.F. 1957. The distribution of stress and velocity in glaciers and ice-sheets. Proc. R. Soc. London, Ser. A, 239(1216), 113-133.

Partington, K. C., W. Cudlip, N.F. McIntyre and S. King-Hele. 1987. Mapping of Amery Ice Shelf, Antarctica, surface features by satellite altimetry. Ann. Glaciol., 9, 183-188.

Sanderson, T.J. O. and C.S. M. Doake. 1979. Is vertical shear in an ice shelf negligible? F. Glaciol., 22(87), 285292.

Snyder, J.P. 1987. Map projections - a working manual. U.S. Geol. Surv. Prof. Pap. 1395.

Whillans, I. M., Y. H. Chen, C.J. van der Veen and T.J. Hughes. 1989. Force budget: III. Application to threedimensional flow of Byrd Glacier, Antarctica. 7. Glaciol., 35(119), 68-80.

Zwally, H.J., R.A. Bindschadler, A. C. Brenner, T. V. Martin and R.H. Thomas. 1983. Surface elevation contours of Greenland and Antarctic ice sheets. 7 . Geophys. Res., 88(C3), 1589-1596.

Zwally, H.J., S. N. Stephenson, R. A. Bindschadler and R.H. Thomas. 1987. Antarctic ice-shelf boundaries and elevations from satellite radar altimetry. Ann. Glaciol., 9, 229-235.

The accuracy of references in the text and in this list is the responsibility of the authors, to whom queries should be addressed. 